\title{
$\mathrm{MIMO}$ 수중통신에서 최적의 터보 등화 기법
}

\author{
김태훈 ${ }^{1} \cdot$ 정지원 $^{* *}$
}

\section{Optimum Turbo Equalization Method based on Layered Space Time Codes in Underwater Communications}

\author{
Tae-hun Kim ${ }^{1} \cdot$ Ji-won Jung ${ }^{2 *}$ \\ ${ }^{1}$ Department of Radio Communication Engineering, Korea Maritime and Ocean University, Busan 606-791, Korea \\ ${ }^{2 *}$ Department of Radio Communication Engineering, Korea Maritime and Ocean University, Busan 606-791, Korea
}

\section{요 약}

수중에서의 음향 통신의 성능은 신호의 다중경로 전달과정에 의해 발생하는 지역 확산 현상으로 인하여 인접간섭 의 영향을 받는다. 그리고 음파를 이용한 주파수의 제한으로 인하여 낮은 전송 속도로 통신을 한다. 따라서 전송속도 의 향상과 함께 인접간섭을 제거하기 위하여 수중 통신에 적합한 시공간 부호화 기술과 등화기 기술, 채널 부호화 기 술이 필요하다. 본 논문에서는 이러한 기술들을 시뮬레이션을 통하여 MIMO 수중 통신 시스템에서 최적의 터보 등 화 기법을 이용한 복호구조를 제안한다. 각 모듈별 시뮬레이션을 통한 성능결과 본 논문에서 제안한 계층적 시공간 부호화 방식 기반의 터보 등화 기법을 이용하면 일반적인 수중 통신 보다 성능이 우수함을 알 수 있다.

\section{ABSTRACT}

The performance of underwater acoustic(UWA) communication system is sensitive to the Inter-Symbol Interference(ISI) due to delay spread develop of multipath signal propagation. And due to limited frequency using acoustic wave, UWA is a low transmission rate. Thus, it is necessary technique of Space-time code, equalizer and channel code to improve transmission speed and eliminate ISI. In this paper, UWA communication system were analyzed by simulation using these techniques. In the result of simulation, the proposed Turbo Equalization method based on layered Space Time Codes has improved performance compared to conventional UWA communication.

키워드 : 수중 음향 통신, MIMO, 시공간 부호, 터보 등화 기법, 터보 부호, BCJR, LMS-DFE

Key word : Underwater acoustic communication, MIMO(Multiple Input Multiple Output), STC(Space Time Codes), Turbo equalization, Turbo codes, BCJR, LMS(Linear Mean Square) - DFE(Decision Feedback Equalizer)

접수일자 : 2014. 02. 21 심사완료일자 : 2014. 03. 18 게재확정일자 : 2014. 03. 31

* Corresponding Author Ji-Won Jung(E-mail:jwjung@kmou.ac.kr, Tel:+82-42-520-5123)

Department of Radio Communication Engineering, Korea Maritime and Ocean University, Busan 606-791, Korea 


\section{I. 서 론}

수중통신에서의 채널의 경우 전달 과정에서 잔향 및 다중경로 등에 의해 크게 왜곡되며, 좁은 대역폭으로 인해 전송률이 낮다. 이러한 오차 유발 요인을 극복하 고 높은 신뢰도 있는 통신을 하기 위해서는 채널 부호 화 기술이 필수적이며 그리고 스펙트럼의 효율성을 높 이고 다이버시티 및 부호화 이득을 동시에 얻으며 높은 전송 효율을 보이는 MIMO (Multiple Input Multiple Output)기술이 현재 연구 중에 있다[1,2].

$\mathrm{MIMO}$ 수중통신 환경에서 다중 센서를 이용하여 다 이버시티 효과 및 부호화 이득을 얻기 위해서는 시공간 부호화(space time code) 방식의 적용이 대두되고 있다. 최근 수중 통신시스템에서는 이러한 열악한 채널환경 을 극복하고 전송률을 향상시키기 위하여 등화기 및 채 널 부호화와 시공간 부호화 방식의 효율적인 연접 구조 기반의 $\mathrm{MIMO}$ 시스템이 적용 및 연구되고 있다. 시공간 부호 중 다이버시티 이득과 함께 부호화 이득을 동시에 가지는 Blum에 의해 제안된 32 상태의 시공간 격자 부 호화 기법을 내부 부호로 하고[3], 터보 부호[4]를 외부 부호로 구성하는 계층적 부호화 방식을 제안한다. 두 시스템의 결합 시 터보 복호기의 입력 값으로는 시공간 격자 복호기를 이용하여 연판정된 비트를 입력 값으로 필요로 한다. 그리고 터보 부호 내부에서만 이루어지는 기존의 방법과는 다르게 시공간 격자 부호의 복호 방식 을 연판정 출력을 위한 BCJR(Bahl, Cocke, Jelinek and Raviv) 알고리즘[5]을 적용하여 터보 복호와 함께 전체 적인 반복을 하여 성능이 향상되는 것을 시뮬레이션을 통하여 확인하였다. 또한 다중 채널 환경에서 반복 기 반의 계층적 시공간 방식의 복호 구조를 등화기와 함께 효율적으로 연접하는 방안과 성능을 시뮬레이션을 통 하여 분석한다. 그리고 최종적으로 계층적 시공간 부 호와 반복 기반의 터보 등화기[6]의 효율적인 결합 방법 및 반복 방안을 모의실험을 이용한 성능 분석을 통하여 제안한다.

\section{ㅍ. 수중 MIMO 시스템 모델}

수중 채널의 다중 경로 극복을 위해서 송수신단의 다 수의 센서를 이용한 다이버시티 효과를 제공하고 대역
폭의 손실 없이 비부호화 시스템보다 이득을 제공하는 $\mathrm{MIMO}$ 기술을 수중 채널 코딩 방식과 함께 접목 시켜야 한다. 수중에서의 다중 채널로 인한 왜곡된 신호를 다 중 센서를 이용하여 서로 보상하며 다이버시티 이득뿐 만 아니라 전송률을 향상 시킬 수 있다. 그림 1 은 일반 적인 $\mathrm{MIMO}$ 시스템 블록도이다.

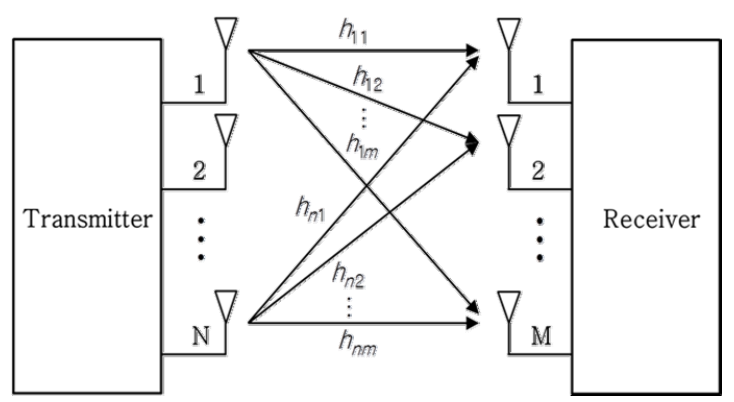

그림 1. 일반적인 $\mathrm{MIMO}$ 시스템 블록도

Fig. 1 The block diagram of general MIMO system

이때 수신된 신호는 식 (1)과 같다.

$r_{j}(k)=\sum_{i=0}^{N-1} h_{i j}(k) * x_{i}(k)+n_{j}(k), \quad(j=0, \cdots, M)$

$r_{j}$ 는 $j$ 번째 수신센서의 수신신호, $x_{i}$ 는 $i$ 번째 송신센 서의 송신신호, $n_{j}$ 는 $j$ 번째 수신센서의 가우시안 잡음 이며, $h_{i j}$ 는 $i$ 번째 송신센서에서 $j$ 번째의 수신센서에 대한 채널 임펄스 응답이다. 송신신호는 각각의 독립된 채널 $h_{i j}$ 와 컨벌루션되어 잡음이 더해지게 된다. 수신 신호를 간략하게 $r_{j}=h_{i j} x_{i}+n_{j}$ 로 나타낼 수 있다. 이 를 행렬로 식 (2), 식(3), 식(4)와 같이 나타낸다.

$$
r=H x+n
$$

$r=\left[\begin{array}{c}r_{1} \\ \vdots \\ r_{m}\end{array}\right] x=\left[\begin{array}{c}x_{1} \\ \vdots \\ x_{n}\end{array}\right] n=\left[\begin{array}{c}n_{1} \\ \vdots \\ n_{m}\end{array}\right]$

$$
H=\left[\begin{array}{cccc}
h_{11} & h_{21} & \cdots & h_{n 1} \\
h_{12} & h_{22} & \cdots & h_{n 2} \\
\vdots & \vdots & \ddots & \vdots \\
h_{1 m} & h_{2 m} & \cdots & h_{n m}
\end{array}\right]
$$


예를 들어 송수신 각각 두 개의 센서의 $\mathrm{MIMO}$ 시스 템에서의 수신신호는 식 (5)와 같다.

$$
\begin{aligned}
& r_{1}=h_{11} \times x_{1}+h_{21} \times x_{2}+n_{1} \\
& r_{2}=h_{12} \times x_{1}+h_{22} \times x_{2}+n_{2}
\end{aligned}
$$

이를 행렬형태로 나타내면 식(6)과 같다.

$$
\left[\begin{array}{l}
r_{1} \\
r_{2}
\end{array}\right]=\left[\begin{array}{l}
h_{11} h_{21} \\
h_{12} h_{22}
\end{array}\right]\left[\begin{array}{l}
x_{1} \\
x_{2}
\end{array}\right]+\left[\begin{array}{l}
n_{1} \\
n_{2}
\end{array}\right]
$$

\section{III. 수중 MIMO 시스템 터보 등화 모델 제안}

본 논문에서는 오류가 집중되어 발생할 경우 오류 를 분산시키는 기능을 하는 인터리버를 외부부호와 시 공간 격자 부호 사이에 첨가하여 효율적인 송신 구조 를 제안한다. 또한 인터리버를 가지는 구조는 외부 부 호의 오류마루 현상을 방지하는 효과도 가지고 있다. 본 논문에서 제시하는 $\mathrm{MIMO}$ 수중채널에서 송수신단 구조는 그림 2 와 같다. 외부부호로는 터보 부호를 적용 시키며, 내부부호로는 시공간 부호화 방식의 구조를 제안한다.

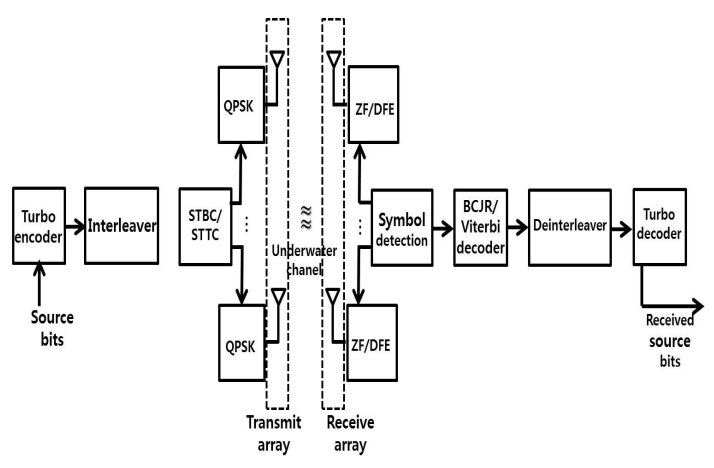

그림 2. $\mathrm{MIMO}$ 수중채널에서의 송수신단 구조

Fig. 2 The structure of $\mathrm{Rx} \& \mathrm{Tx}$ in MIMO underwater channel

\section{1. 시공간 부호화 방식 및 복호화 방식}

그림 2에서 보면 시공간 부호는 크게 전송 다이버시 티와 부호화 이득을 동시에 가지는 시공간 격자 부호와 부호화 이득은 없고 전송 다이버시티만 가지는 시공간
블록 부호로 나눌 수 있다[7]. 시공간 블록 부호는 부호 화 이득은 없지만 최적의 다이버시티 이득과 함께 간단 하게 부·복호기를 구성할 수가 있다. 하지만 열화된 성 능의 복원을 필요로 하는 수중 통신에서는 부호화 이득 을 가지는 시공간 격자 부호 기술이 더 적합하다. 최근 수중 통신시스템에서는 이러한 열악한 채널환경을 극 복하고 전송률을 향상시키기 위하여 등화기 및 채널 부 호화와 시공간 부호화 방식의 효율적인 연접 구조기반 의 $\mathrm{MIMO}$ 시스템이 적용 및 연구되고 있다[8]. 시공간 격자 부호 중 다이버시티 이득과 함께 부호화 이득을 동시에 가지는 Blum에 의해 제안된 32 상태의 시공간 격자 부호화 기법을 내부 부호로 적용하고자 한다. Blum이 제안한 32 상태의 부호화[3] 식은 아래 식 (7)과 같다.

$$
\begin{aligned}
r_{1}(t)= & 2 \times\left(a_{2}(t-\tau) \oplus a_{1}(t-2 \tau) \oplus a_{2}(t-2 \tau) \oplus a_{1}(t-3 \tau)\right) \\
& +\left(a_{2}(t-2 \tau) \oplus a_{1}(t-\tau)\right) \\
r_{2}(t)= & 2 \times\left(a_{2}(t) \oplus a_{2}(t-\tau) \oplus a_{2}(t-2 \tau) \oplus a_{1}(t-3 \tau)\right) \\
& +\left(a_{2}(t-2 \tau) \oplus a_{1}(t-\tau) \oplus a_{1}(t)\right)
\end{aligned}
$$

$a_{1}(t), a_{2}(t)$ 는 $\mathrm{t}$ 시점에서 시공간 격자 부호기의 입력 비트이고, $a_{i}(t-\tau)$ 는 $\mathrm{i}$ 번째 입력 신호의 $\tau$ 만큼 지연된 신호이다. 따라서 QPSK의 심볼로 4개의 위상점 $\{0,1$, $2,3\}$ 을 나타내기 위해 식 (7)과 같이 나타내었다.

시공간 부호화되어 전송되어진 $\mathrm{i}$ 번째 수신센서의 수 신신호 $r_{i}$ 는 식 (1)과 같이 정의하였다. 복호를 위하여 비터비 복호기 혹은 BCJR 복호기에 입력된다. 격자구 조 기반의 전송 신호는 비터비 복호기로 복호 할 수 있 으며, 이의 출력은 경판정된 신호 형태이므로 터보복호 기 입력 시 성능 저하를 야기시킬 수 있다. 이에 본 논문 에서는 비터비 복호기의 출력을 연판정 가능한 BCJR 복호 방식을 시공간 격자 부호화 방식에 적용시켰다. $\mathrm{BCJR}$ 복호기에서는 $\mathrm{BM}$ (branch matric), $\mathrm{FSM}$ (forward state matric), BSM(backward state matric)을 구하 기 위하여 입력 값에 따른 출력 값과 함께 변화하는 상 태를 나타내는 격자도를 이용한다.

$\mathrm{BCJR}$ 연산에 있어 유한한 이전상태, 채널 출력, 다음상태가 존재한다. 이전 상태는 $s^{\prime}$, 현재 상태는 $s=\left(x_{j-m}, x_{j-m+1}, \cdots, x_{j}, x_{j+1}, \cdots, x_{j+m}\right)$ 로 주어지며, 전송된 신호는 $x=\left(x_{1}, x_{2}, \cdots, x_{n}\right)$, 수신 신호는 
$r=\left(r_{1}, r_{2}, \cdots, r_{n}\right)$ 로 표현하면, 전송신호 $x_{j}(j=1,2, \cdots, n)$ 에 대한 LLR값은 식 (8)과 같이 나타낸다.

$$
\begin{aligned}
L\left(u_{j}\right) & =\max ^{*}\left[\alpha_{j-1}\left(s^{\prime}\right)+\gamma_{j}\left(s^{\prime}, s\right)+\beta_{j}(s)\right]\left(s^{\prime}, s\right): x_{j}=0 \\
& -\max ^{*}\left[\alpha_{j-1}\left(s^{\prime}\right)+\gamma_{j}\left(s^{\prime}, s\right)+\beta_{j}(s)\right]\left(s^{\prime}, s\right): x_{j}=1
\end{aligned}
$$

$\mathrm{FSM}$ 은 식 (8)에 의해 $\alpha_{j}(s)=\log p\left(s_{j}=s, r_{1}^{j}\right)$ 로 나 타낼 수 있다.

$$
\alpha_{j}(s)=\max ^{*}\left[\alpha_{j-1}\left(s^{\prime}\right)+\gamma_{j}\left(s^{\prime}, s\right)\right]
$$

$\mathrm{BSM}$ 은 식(8)에 의해 $\beta_{j}(s)=\log p\left(r_{j+1}^{n} \mid s^{\prime}=s\right)$ 로 주어진다.

$$
\beta_{j-1}\left(s^{\prime}\right)=\max ^{*}\left[\beta_{j}(s)+\gamma_{j}\left(s^{\prime}, s\right)\right]
$$

$\mathrm{BM}$ 은 식 (11)과 같다.

$$
\begin{aligned}
\gamma_{j}\left(s^{\prime}, s\right) & =\log p\left(s_{j}=s, r_{j} \mid s_{j-1}=s^{\prime}\right) \\
& =\log p\left(r_{j} \mid x_{j}\right) p\left(x_{j}\right)
\end{aligned}
$$

$\max ^{*}$ 는 식 (12)로 정의된다.

$$
\max ^{*}(x, y)=\max (x, y)+\log \left(1+e^{|x-y|}\right)
$$

\section{2. 터보 등화 기법}

그림 2의 송신 구조는 터보 부호와 시공간 격자 부호 사이에 인터리버를 접목시키는 구조이며 터보 부호화 를 거친 비트 스트림은 인터리버 후에 시공간 격자 부 호에 입력된다. 송신된 신호는 다중경로 채널을 통과하 여 수신되어진다. 수신 신호는 채널 추정과 등화기를 통하여 복원된 송신신호가 합쳐져서 $\mathrm{BCJR}$ 복호기로 입력되어진다. 시공간 격자 복호단에서 $\mathrm{BCJR}$ 복호기 를 통하여 수신 비트 스트림 크기만큼의 $\operatorname{LLR}(\log$ Likelihood Ratio) 값이 출력된다. BCJR 의 복호 방식은 터보 부호의 복호 방식과 동일하며, 각 상태에서 ' 0 '의 확률과 ' 1 '의 확률을 계산하여 $\mathrm{FSM}, \mathrm{BSM}$ 을 계산하여 최종적으로 값을 계산한다. 추정되어진 LLR 값은 역인터리버를 통하여 송신단에서의 인터리버 이전의 주
소로 재배치하여 터보 복호기에 입력된다[4]. 이러한 반 복 구조를 터보 등화 기법이라 하며, 이를 MIMO 수중 통신에 제안함으로써 다중경로 채널 환경에서 전송률 을 높일 수 있다.

시공간 격자 복호단에서 BCJR 복호기를 통하여 수 신 비트 스트림 크기만큼의 LLR 값이 출력된다. 추정 되어진 LLR 값은 역-인터리버를 통하여 송신단에서의 인터리버 이전의 주소로 재배치하여 터보 복호기에 입 력된다. 일반적인 터보 복호기는 복호기 내부 반복을 통하여 성능을 향상시키는 구조이지만, 본 논문에서 제 안하는 복호기 구조는 터보 복호기에서 계산되어 추정 된 LLR 값을 다시 인터리버를 통하여 BCJR 복호기에 업데이트 시켜주는 방식이다. BCJR 복호기에 업데이 트 되어진 LLR 값을 이용하여 BCJR 복호기에서는 새 로이 추정된 $\mathrm{BCJR} \mathrm{LLR}$ 값을 계산하게 된다. 추정된 $\mathrm{BCJR}$ LLR값은 이전에 터보 복호기의 LLR 값과의 차 를 구하여 역-인터리버 후에 터보 복호기에 새로이 입 력되게 된다. 따라서 전체 반복을 통하여 터보 복호기 와 BCJR 복호기가 함께 업데이트 되므로 터보 복호기 내부에서만 반복을 하였을 때보다 부호화 이득이 향상 된다.

\subsection{MIMO 시스템에서 채널 등화 기법}

$\mathrm{MIMO}$ 통신 기반의 다중 채널 환경인 수중 통신에서 는 다중 채널로 인한 서로 독립된 다중경로를 이루고 있어 반복기반의 계층적 복호 구조를 적용하기 위해서 는 등화기 기술의 적용이 필요하다. MIMO 시스템에서 적용가능한 등화기 기술로는 $\mathrm{ZF}$ (Zero Forcing) 검출법 을 이용한 등화기와 LMS-MMSE 검출법을 이용한 등 화기, $\mathrm{LMS}-\mathrm{DFE}$ 를 이용한 등화기 등이 있다. $\mathrm{LMS}$ -MMSE 등화기와 ZF 등화기는 훈련 심볼열을 이용하 여 등화기의 탭 계수 값을 고정하여 사용하는 선형 등 화 기법이다 [9].LMS- MMSE 등화기 보다 구조가 간단 하며 복잡도가 낮은 역함수를 이용하는 ZF 등화기와 훈 련 심볼열을 이용하여 먼저 등화기의 탭 계수 값을 고 정하고 입력 데이터가 들어오면 결정 지향 모드로 변환 하여 데이터를 이용해 채널을 추정하고 등화과정을 반 복하는 비선형 등화기인 LMS-DFE 등화기 $[10,11]$ 가 더욱더 효율적일 수 있다. 


\section{$\mathrm{IV}$. 수중 채널 모델}

다중 채널을 가지는 MIMO 시스템에서의 등화기 성 능 분석 및 반복기반의 최적의 복호 구조에 대한 성능 을 분석하기 위하여 실제 동해상에서 실험을 통하여 얻 은 SVP(Sound Velocity Profile)를 기초로 하여 채널을 생성한 후 모의 실험을 통하여 시뮬레이션 하였다. 실 험 해역의 수심은 $200[\mathrm{~m}]$ 이고, XBT(eXpandable Bathy Thermograph)를 이용하여 그림 3의 SVP를 구하였다.

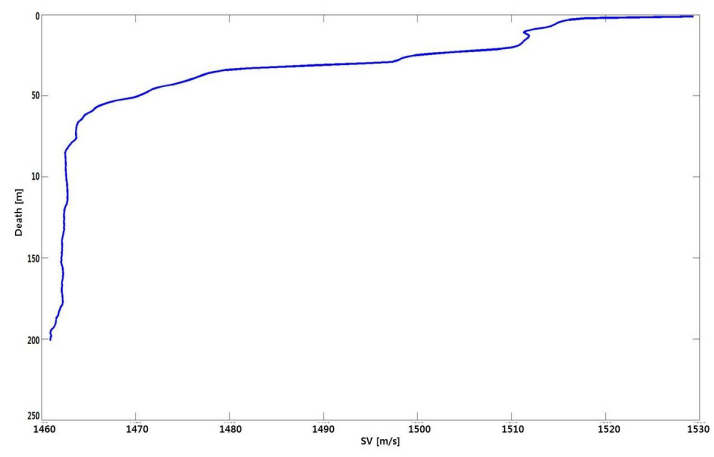

그림 3. MIMO 실험을 통해 얻은 SVP

Fig. 3 The SVP for MIMO experiment

이를 바탕으로 각 채널의 전달 함수 $h_{i, j}$ 을 얻기 위하 여 Matlab을 기반으로 한 Ray 모델링 프로그램을 사용 하였으며, $2 \times 2 \mathrm{MIMO}$ 통신을 위하여 그림 4 와 같이 송신기의 깊이는 $\mathrm{Tx} 1=110[\mathrm{~m}], \mathrm{Tx} 2=117[\mathrm{~m}]$ 이고 수신 기의 깊이는 $\mathrm{Rx} 1=110[\mathrm{~m}], \mathrm{Rx} 2=117$ [m]에서 결과를 도출하였다. 송·수신기간의 거리는 $1[\mathrm{~km}]$ 이다. 모의실 험을 위해 적용된 각각의 채널 응답은 그림 5 와 같다.

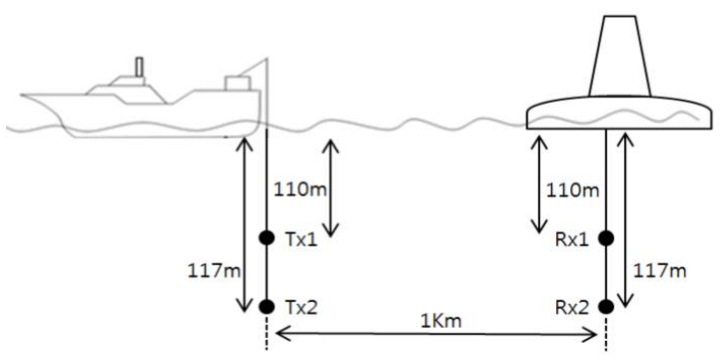

그림 4. 모의실험을 위한 송수신기 배치

Fig. 4 The Tx and Rx scheme for experiment
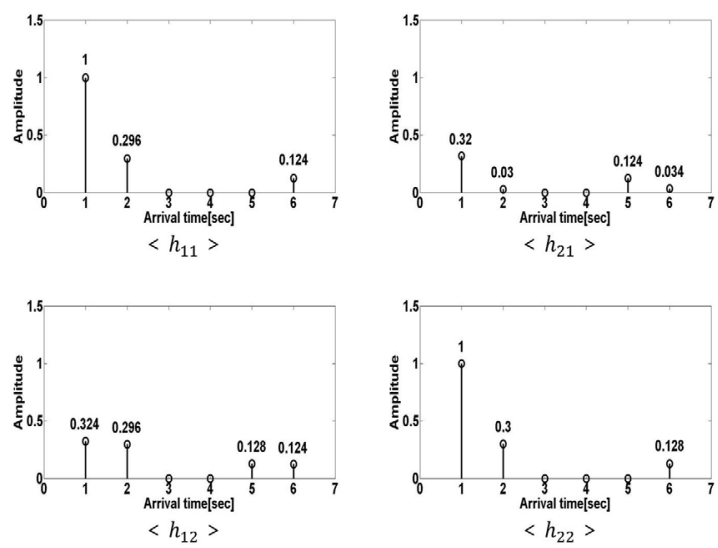

그림 5. 각각의 채널 응답

Fig. 5 The delay profile at each channel

\section{$\mathrm{V}$. 시뮬레이션 결과 및 최적의 터보 등화 기법 구조}

\section{1. 시공간 부호화 방식에 따른 성능}

모든 시뮬레이션은 그림 5 의 채널 환경을 토대로 실 시하였다. 그림 6 은 시공간 격자 부호와 시공간 블록 부 호의 시뮬레이션 결과 성능 비교 그래프이다. 시뮬레이 션에서 사용한 터보 부호화기는 전송 bit의 $\mathrm{K}=984$ 크기, 부호화율 $\mathrm{R}=1 / 3$ 을 사용하였다. 시뮬레이션 환경은 심 볼 주기 $\mathrm{T}$ 동안 서로 독립적인 분포를 가지는 다중경로 채널로써 주기 $\mathrm{T}$ 동안 채널의 변화가 없고, 수신단에서 는 채널 추정을 정확히 알고 있다고 가정하였다. 변조 방식은 QPSK 변조방식을 적용하였다.

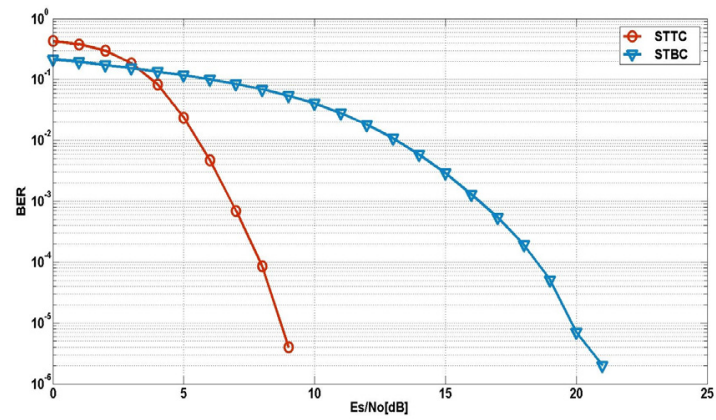

그림 6. 시공간 격자부호와 시공간 블록 부호의 성능비교

Fig. 6 The performance comparison of STTC and STBC 
시뮬레이션 결과 $B E R=10^{-4}$ 에서 시공간 부호기법 중 시공간 격자 부호가 시공간 블록 부호보다 약 10 $[\mathrm{dB}]$ 성능이 좋다는 것을 알 수 있다. 이는 다중경로 채 널에서 시공간 격자 부호의 시공간 기법이 더욱 적합하 다고 할 수 있다.

\section{2. 복호 방식에 따른 성능}

채널 등화 후의 출력 값이 시공간 격자 복호기로 입 력될 때 시공간 격자 복호기에서는 일반적으로 비터비 복호 알고리즘을 사용한다. 이러한 비터비 복호 알고 리즘은 수신 비트를 '-1' 또는 ' +1 '로 강판정을 하여 복 호 과정을 통하여 강판정된 값을 출력하게 된다. 이렇 게 강판정된 값은 연판정된 입력 값을 요구하는 터보 복호기에 입력되어 성능의 열화 및 터보 호기 내에서 의 반복을 통한 성능 향상을 저해하는 요소로 작용한 다. 따라서 제안된 계층적 시공간 부호기의 시공간 복 호에서 연판정 복호를 하기위해 BCJR 복호기를 사용 한다.

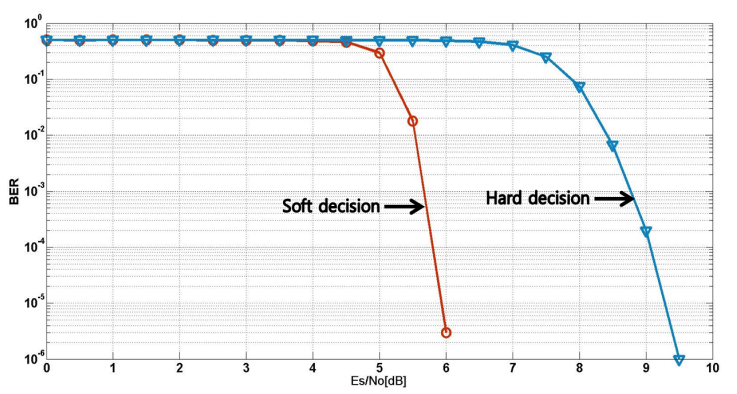

그림 7. 연판정(BCJR)과 강판정(Viterbi) 복호기의 성능비교 Fig. 7 The performance comparison of soft decision and hard decision

시뮬레이션 결과 $B E R=10^{-4}$ 에서 연판정된 값이 복호기에 입력되었을 때가 약 $3[\mathrm{~dB}]$ 정도 성능이 좋다 는 것을 알 수 있으며, 따라서 연판정된 출력 값을 가지 는 $\mathrm{BCJR}$ 복호기를 사용하여야한다. 연판정된 $\mathrm{BCJR}$ 복 호기의 값이 터보 복호기로 입력되어져 터보 복호기에 서의 반복 복호를 통하여 데이터를 복호하게 된다.

\section{3. 등화기에 따른 성능}

다중 채널을 가지는 $\mathrm{MIMO}$ 수중 환경에 적합한 등화 기법을 제시하기 위하여 ZF 등화기와 LMS-DFE 등화
기를 이용하였을 때의 각각의 성능을 그림 5 의 채널 응 답을 이용하여 시뮬레이션 하였다. 그림 8 은 이에 따른 $\mathrm{BER}$ 성능을 나타내고 있다.

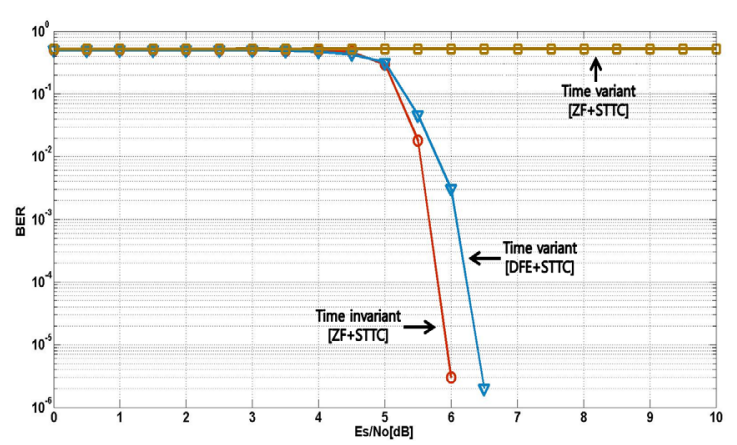

그림 8. ZF와 LMS-DFE 등화기의 성능비교

Fig. 8 The performance comparison of ZF and LMSDFE

채널 부호화 이득과 함께 시공간 부호의 다이버시티 이득으로 인하여 ZF 등화기와 BCJR 복호기를 이용하 는 계층적 시공간 부호를 이용한 구조에서는 BER $10^{-4}$ 을 기준으로 $E b / N o=5.8[\mathrm{~dB}]$ 에서 만족할만한 성능 을 보이고 있다. 하지만 채널 응답이 시변 할 때는 성능 그래프의 시변 채널에서의 $\mathrm{ZF}$ 와 계층적 시공간 부호의 성능과 같이 오류를 개선하지 못하는 선형 등화기의 단 점이 나타난다. 이는 ZF 선형 등화기를 빠르게 시변 하 는 다중 채널 환경에 적용하기 위해서는 패킷 설계 시 에 채널 응답을 추정하기 위하여 사용되는 훈련 심볼열 의 길이가 길어야 되고, 전송하고자 하는 데이터 심볼 열을 작게 하여 채널 응답의 변동이 나타나지 않는 범 위의 시간 내에서 전송하여야 한다. 실제 다중 채널 환 경인 수중 통신에서는 빠르게 시변 하는 채널 응답을 보이고 있다. 따라서 전송 효율을 향상시키고 높은 신 뢰도의 데이터를 획득하기 위해서는 훈련 심볼열을 이 용하여 등화기의 탭 계수 값을 최적화한 후 채널 응답 의 변동이 발생하더라도 입력 데이터를 이용하여 결정 지향 모드로 변환하여 패킷의 데이터를 이용해 채널을 추정하고 등화과정을 반복하게 되는 LMS-DFE 등화기 가 더 적합하다. LMS-DFE 등화기를 이용한 계층적 시 공간 부호는 채널이 시변하더라도 BER $10^{-4}$ 을 기준으 로 $\mathrm{Eb} / \mathrm{No}=6.3[\mathrm{~dB}]$ 의 성능을 보이기 때문에 $\mathrm{ZF}$ 등화 기 보다 약 $0.5[\mathrm{~dB}]$ 의 BER 효율면에서는 감소하더라 
도 시변 채널을 가지는 수중 통신 환경에 더 적합한 것 을 알 수 있다.

\section{4. 반복 구조에 따른 성능}

$\mathrm{MIMO}$ 수중 통신에서 효율적인 통신 시스템을 위해 서는 제안된 계층적 시공간 부호에서 BCJR 알고리즘 복호 방안 및 LMS-DFE 등화기의 구조가 적합하다. 따 라서 본 논문에서는 그림 2에서의 일반적인 복호기 구 조가 아닌 계층적 시공간 부호안에서의 연판정된 출력 값을 이용한 효율적인 반복 복호 구조를 제안한다. 그 림 9는 제안하는 반복 복호 기반의 최적의 복호 구조를 나타내고 있다.

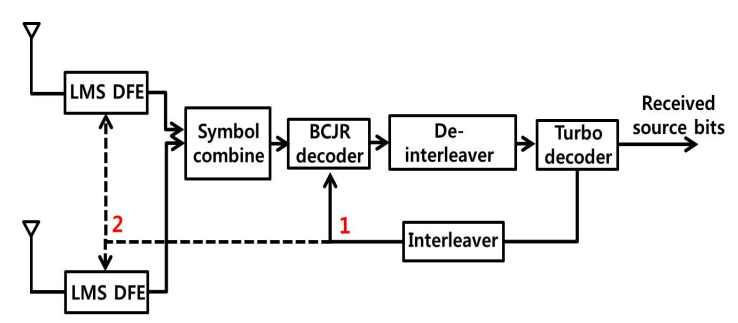

그림 9. 제안하는 최적의 반복 복호 구조

Fig. 9 The structure of optimal iterative decoding

일반적으로 연구되어져 있는 LMS-DFE 등화기와 시 공간 부호간의 반복을 통한 복호 방법은 그림 9 에서의 2 번과 같은 Outer iteration 방법으로써 LMS-DFE 등화기 와 시공간 격자 복호 방법으로 비터비 알고리즘으로 사 용되고 있다. 본 논문에서 제안하는 반복 복호 구조는 시공간 격자 복호기로 $\mathrm{BCJR}$ 알고리즘을 이용하여 LMS-DFE 등화기와의 반복이 아닌 터보 부호와의 반 복을 통하여 채널 부호 이득을 향상 시킬 수 있는 1 번과 같은 Inner iteration을 이용하는 방법을 제안한다.

본 논문에서 제안한 Inner iteration을 통한 성능의 향 상을 검정하기 위하여 그림 5 의 채널 응답을 이용하여 모의실험을 통하여 BER 성능을 시뮬레이션 하였다. 그 림 10 은 제안하는 Inner iteration 복호에 따른 성능 및 일반적인 Outer iteration 복호에 따른 성능을 나타내고 있다.

시뮬레이션 결과 효율적인 반복을 통한 복호 구조에 따른 성능이 반복이 없는 복호 구조 보다 향상됨을 알 수 있다. 또한 반복 방안으로 제안한 Inner iteration을 이용한 터보 부호와 $\mathrm{BCJR}$ 알고리즘을 이용한 시공간
격자 복호 이용하였을 때의 성능이 일반적인 LMS-DFE 등화기와 시공간 격자 복호 방법으로 비터비 알고리즘 으로 사용하여 Outer iteration을 이용한 반복 보다 낮은 $E s / N o$ 에서 성능이 조금 더 향상되는 것을 알 수 있다. 반복 복호에서 성능을 향상시키기 위해서는 반복 시에 사용되는 복호기의 출력 값이 신뢰도 있는 정보에 가까 울수록 성능이 향상된다. 따라서 Inner iteration을 이용 한 반복 복호는 낮은 $E s / N o$ 에서 터보 부호기의 높은 부호화 이득을 가지는 출력 값으로 Outer iteration을 하 는 방법보다 BER 성능이 더 우수하다.

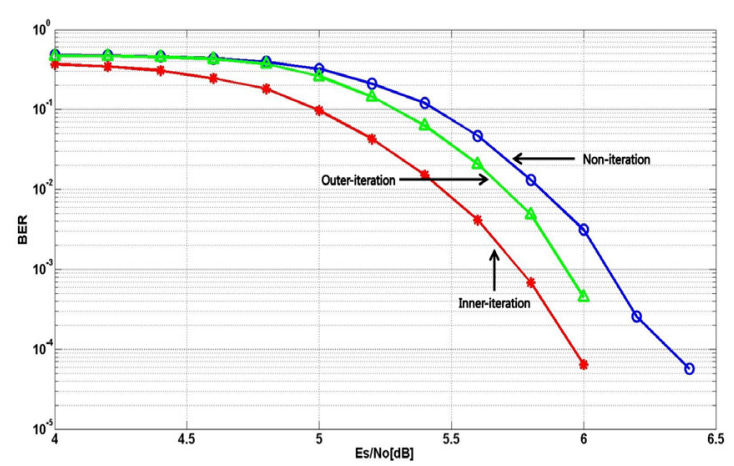

그림 10. 반복 방식에 따른 성능

Fig. 10 The performance graph according to iteration method

\section{VI. 결 론}

본 논문에서는 $\mathrm{MIMO}$ 수중 통신시스템에서 열악한 채널환경을 극복하고 전송률을 향상시키기 위하여 등 화기 및 채널 부호화와 시공간 부호화 방식의 효율적인 연접 구조기반의 복호구조를 연구하였다. 외부 부호로 는 터보 부호를 고정하여 시공간 부호화 방식을 내부 부호로 그리고 수신단에서 효율적인 반복모델을 제시 하기 위해 다양한 방식별로 시뮬레이션 하여 최적의 모 델을 제시하였다. 시공간 부호화 방식을 정하기 위하여 시공간 블록 부호와 시공간 격자부호의 성능을 시뮬레 이션한 결과 $B E R=10^{-4}$ 에서 시공간 격자 부호가 시 공간 블록 부호보다 약 $10[\mathrm{~dB}]$ 만큼 성능이 우수하다 는 것을 알 수 있었다. 또한 시공간 격자 부호를 복호할 때 강판정된 값을 출력하는 비터비 복호기와 연판정 복 호기인 BCJR 복호기를 사용하였을 때의 성능을 시뮬 
레이션을 통해 비교한 결과, $B E R=10^{-4}$ 에서 연판정 복호를 하기위한 $\mathrm{BCJR}$ 복호기가 약 $3[\mathrm{~dB}]$ 가량 우수 하다는 것을 알 수 있었다. 최적의 등화 기법으로 시변 채널에서 좋은 성능을 나타내는 LMS-DFE 등화기를 제시하였다. 수신부의 반복 복호구조에서 제안한 계층 적 시공간 부호 안에서의 연판정된 출력 값을 이용한 효율적인 Inner iteration 복호 구조가 성능이 우수함을 알 수 있다.

최종적으로 $\mathrm{MIMO}$ 수중 통신 기반의 효율적인 전송 기법의 구조로는 LMS-DFE 등화기와 함께 시공간 격 자 부호, 그리고 터보 부호를 연접하였을 때 최적의 성 능을 보이는 것을 알 수 있었고, 또한 $\mathrm{MIMO}$ 시스템에 서의 최적의 반복 구조는 제안된 시공간 격자 부호와 터보 부호간의 Inner iteration 복호 구조가 적합함을 알 수 있었다.

\section{감사의 글}

“본 연구는 방위사업청과 국방과학연구소의 지원 (계약번호 UD110101DD)으로 수행되었습니다.” “본 연구는 교육과학기술부와 한국연구재단의 지 역혁신인력양성사업으로 수행된 연구결과임.”

\section{REFERENCES}

[1] G. Ungerboeck, "Channel coding with multi level/phase signals," IEEE Trans. on Information Theory, Vol. IT-28, No. 1, 1982.
[2] M. J. Gans, G. J. Foschini, "On limits of wireless communication in a fading environment when wsing multiple antennas," Wireless Personal Communication, Vol. 5, No. 3, pp. 311-335, 1998.

[ 3 ] R. S. Blum, X. Lin, "Improved space-time codes using serial concatenation", IEEE Communication Letter, Vol. 4, pp. 221-223, 2000.

[4] C. Berrou, A. Glavieux, and P. Thitimajshima, "Near Shanon Limit Error-Correcting Coding and Decoding : Turbo-Codes", in Proc. ICC9, 1993.

[ 5 ] L. Bahl, J. Cocke, F. Jelinek, and J. Raviv, "Optimal Decoding of Linear Codes for minimizing symbol error rate", IEEE Transactions on Information Theory, vol. IT-20(2), pp. 284-287, 1974.

[6] M. Tuchler, et al. "Turbo Equalization : Principles and New Results," IEEE Trans. Communications, Vol. 50, No. 5, pp. 754-767, 2002.

[7] S. Alamouti, "A simple transmit diversity technique for wireless communications," IEEE J. Select. Areas Commun., vol. 16, pp. 1451-1458, Aug. 1998.

[ 8 ] Jung, Ji Won, and Ki Man Kim. "Optimizing of Iterative Turbo Equalizer for Underwater Sensor Communication." International Journal of Distributed Sensor Networks 2013, 2013.

[9] Q. H. Spencer, A. L. Swindlehurst, and M. Haardt, "Zero-forcing methods for downlink spatial multiplexing in multi-user MIMO channels," IEEE Transactions on Signal Processing, vol. 52, no. 2, February 2004.

[10] J. Salz, "Optimum Mean-Square Decision Feedbac Equalization," BSTJ, 52, No. 8 (October 1973), p. 1341-73. 4.

[11] K. Berberdis, T. Rontogiannis and S. Theodoridis, "Efficient block implementation of the LMS based DFE," Proceedings 13th Digital Signal Processing International Conference, Vol.1, pp. 143-146, July 1997.

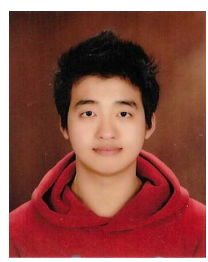

김태훈(Tae-Hun Kim)

약력

2013년 2월 : 한국해양대학교 전파공학과(공학사)

2013년 3월 현재 : 한국해양대학교 전파공학과 석사과정

※관심분야 : 위성 통신, 이동 통신, 수중 통신, 변 · 복조 기술, 채널코딩, FPGA 기술 등 
한국정보통신학회논문지(J. Korea Inst. Inf. Commun. Eng.) Vol. 18, No. 5 : 1042 1050 May. 2014

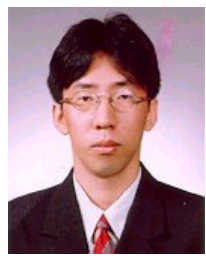

정지원(Ji-Won Jung)

1989년 2월 : 성균관대학교 전자공학과(공학사)

1991년 2월 : 성균관대학교 전자공학과(공학석사)

1995년 2월 : 성균관대학교 정보공학과(공학박사)

1991년 1월 1992년 2월 : LG 정보통신 연구소 연구원

1995년 9월 1996년 8월 : 한국통신 위성통신연구실 선임연구원

1997년 3월 1998년 12월 : 한국전자통신연구원 초빙연구원

1996년 9월 현재 : 한국해양대학교 전파공학과 정교수

2001년 8월 2002년 8월 : 캐나다 NSERC Fellowship(Communication Research Center 근무)

※관심분야 : 위성 통신, 이동 통신, 수중 통신, 변 · 복조 기술, 채널코딩, FPGA 기술 등 